\title{
Is long-serving teaching experience a barrier of transformation in online teaching? - An exploration
}

\author{
Dr.D.Anitha ${ }^{1}$, Dr.D.Kavitha ${ }^{2}$ \\ ${ }^{1}$ Assistant Professor, Dept. of Applied Mathematics and Computational Science, Thiagarajar College of Engineering, Madurai \\ ${ }^{2}$ Assistant Professor, Department of Electrical and Electronics Engineering, Thiagarajar College of Engineering, Madurai \\ 1 anithad@tce.edu \\ ${ }^{2}$ dkavitha@tce.edu
}

\begin{abstract}
Online teaching, an inevitable part of education in 2020, has its own advantages and disadvantages with respect to the perspectives of student and teachers. Every teacher has been in a situation to transform suddenly to the fluctuating needs of education in the COVID 19 crisis. Is this transformation quick and easy for all the teachers? This is an important question that may depend on number of factors including teachers' teaching experience, economic and social background, and skills in teaching tools, motivation and attitude. This research study looks into the parameter "Teaching experience" and attempts to find whether teaching experience stands as an influencing factor in the transformation process. As learning new is always easier than unlearning, this parameter is critically important in analysing whether the long-time experience affects the rate of transformation to online teaching. The research is conducted as a qualitative research with surveys obtained from students and faculty of the host institution after the first cycle of online teaching (after May 2020). 66 teachers and 215 students from various engineering disciplines participated in the survey. Observations from the survey are analysed in different elements of online learning. This study compares the expectations of students and the preference of teachers in these elements. From the study, it has been inferred that teaching experience has a significant impact on the transformation of teachers to meet the students' expectations in the perspective of online teaching. The study also enables suitable recommendations for need based training programs.
\end{abstract}

Keywords: Online teaching, Teaching experience, Online activities, Transformation, Student expectation

\section{Corresponding Author}

Dr. D. Anitha, Assistant Professor in Data Science,

Department of Applied Mathematics and Computational Science,

Thiagarajar College of Engineering, Madurai. anitha@tce.edu

\section{Introduction}

Education is a field which faces lesser disruptions in terms of economic, political and market demands than any other field. There exist progressively evolving developments in inter disciplinary curriculum development to meet the holistic needs of the learners, different pedagogical interventions such as active \& collaborative learning using various ICT tools and assessments with innovative evaluation methods. Teachers have been slowly moving ahead to teaching using technology. But, the large wave of COVID 19 pandemic has suddenly altered the conventional method of teaching and turns itself as a major disruption that ever happened to the teaching community. The commotion has forced conventional teachers to transform themselves into new avatars as online teachers. It has become mandatory for the teachers to exercise online teaching tools rapidly with available infrastructure.

Transforming from a conventional method of teaching to a different form of teaching will be easy only if the person has already exercised the relevant tools and techniques (Sun, Strobel \& Newby, 2017). It is also essential the usage of the technology tools meets the students' expectations. But with little or no experience of the tools and techniques, the task of transforming oneself is not going to be smooth. However, there are some factors that may help teachers to switch to the new mode of teaching. By observing various research studies, there are many personal and socio-economic factors that have influence on the transformation in teaching in terms of usage of technology tools including expertise level, attitude, teaching experience, infrastructure and organizational motivation. Among these factors, personal factors such as technical expertise, attitude and teaching experience are found to be influential in the usage of technology tools (Bingimlas, 2009; Inan \& Lowther, 2010; Windes \& Lesht, 2014; Batane \& Ngwako, 2017). This research study is interested in finding out the influence of the variable "Teaching experience" in this picture. This study tries to find out the answer for the question "Is long-serving teaching experience a barrier of transformation in online teaching?" with appropriate methods and materials.

\section{Literature review}

Online teaching, as perceived in a study in year 2006, has forecasted the online learning with video interactions and blended learning after analysing an online survey (Kim \& Bonk, 2006). There have been many research works undertaken to find the rate of transformation of using technology in teaching since 2004. A review has analysed 
many factors of teachers influencing successful integration of ICT in teaching and learning environment and has found negative attitude, lack of confidence and training stand as barrier for the same (Bingimlas, 2009). There are some studies that the teachers' experience has an effect on the efficacy of the usage of ICT. A doctoral study has revealed that the teacher's long-service experience is not correlated with their technology integrations (Hall, 2008). Face-to-face interactions are preferred by experienced teachers than to online teaching in some research studies (Conrad, 2004, Windes \& Lesht, 2014). A recent study has used five-point Likert scale survey experiment with 55 teachers and has found that conventional teachers have lower intention of using technology (Han, Shin \& Ko, 2017). A research work concludes that age and years of teaching has significant negative influences on the usage of technology after analysing 1382 teachers with hypothesis checking (Inan \& Lowther, 2010).

There are also few studies that show that there is no significant impact of teachers' age, gender and experience in use of ICT (Mahdi \& Al-Dera, 2013, Teo \& Zhou, 2014; Batane \& Ngwako, 2017). However, Batane's work has experimented with the teachers within the age group of 20 to 29, while Mahdi's work has only considered 46 teachers. All these studies are qualitative studies that use surveys and interviews as the data collection tool (Han, Shin \& Ko, 2017). None of the above studies have taken student's expectations on different online elements. Hence, it becomes important to know the influence of teaching experience in learning technology tools preferred by students and thus, leading to insights on essential training programs that may be offered to the teachers (Wilson \& Stacey, 2004).

\section{Research Questions}

With the above literature study and identified need of analysing the influence of teaching experience in the swift transformation, the following research questions have been formulated for the research.

RQ1. What are the expectations of student in terms of learning materials, content delivery and assessment in online learning environment?

RQ2. What is the influence of teaching experience in teachers for transforming themselves to the student expectations in the context of online teaching?

\section{Methods and materials}

This research is proposed as a qualitative analysis and hence surveys are used as major elements for data collection. The research is conducted with the teachers and students of Thiagarajar College of Engineering, Madurai, India. 215 students and 66 teachers of the institution have participated in the survey. The teachers are grouped according to their total years of teaching experience as given in Table 1 as recommended in a research work (Inan \& Lowther, 2010).

Table 1. Grouping of teachers

\begin{tabular}{|l|l|l|}
\hline Group Name & Years of experience & No. of teachers \\
\hline G1 & $0-10$ & 19 \\
\hline G2 & $11-15$ & 14 \\
\hline
\end{tabular}

\begin{tabular}{|l|l|l|}
\hline G3 & $16-20$ & 15 \\
\hline G4 & $>20$ & 18 \\
\hline
\end{tabular}

Two different survey questionnaires are launched during the period of June 2020 to August 2020, one for the teachers and another for the students. Both the questionnaires address the different elements of the three fundamental components of online teaching: Lecture materials, content delivery methods and assessment methods. Table 2 lists the different elements of these three fundamental components considered for the survey questionnaire.

Table2. Survey elements of online teaching components

\begin{tabular}{|l|l|}
\hline \multicolumn{1}{|c|}{ Component } \\
\hline $\begin{array}{l}\text { Learning } \\
\text { material }\end{array}$ & $\begin{array}{l}\text { Self-recorded Videos, YouTube links by } \\
\text { external experts, E book, Specially designed } \\
\text { e-notes }\end{array}$ \\
\hline $\begin{array}{l}\text { Content } \\
\text { delivery }\end{array}$ & $\begin{array}{l}\text { 1) Usage of interactive tools (Online tools, } \\
\text { chat box, Whatsapp) } \\
\text { 2) Collaborative activities (Whether practiced } \\
\text { or not) }\end{array}$ \\
\hline Assessment & $\begin{array}{l}\text { Quiz, Collaborative assignments, Open book } \\
\text { tests, Homework, Graded discussions }\end{array}$ \\
\hline
\end{tabular}

Students are asked to prioritize their preferred elements in these components. Teachers have been asked to provide the data about the online elements that they have used for online teaching. The survey consists of multiple-choice questions, multi answer questions, Yes/No and ranking questions. Student survey questionnaire is available at https://docs.google.com/forms/d/11G6aSzgrccILq7qsnoNN RhopVkAoYG5TDI5-fCxG4Ro/edit . Figure 1 shows a sample screenshot of the form launched to the students. Data collection from teachers is made through Survey Monkey tool (https://www.surveymonkey.com/r/BJB52MC). Table 3 shows the parameters considered from the teachers' survey elements for this study.

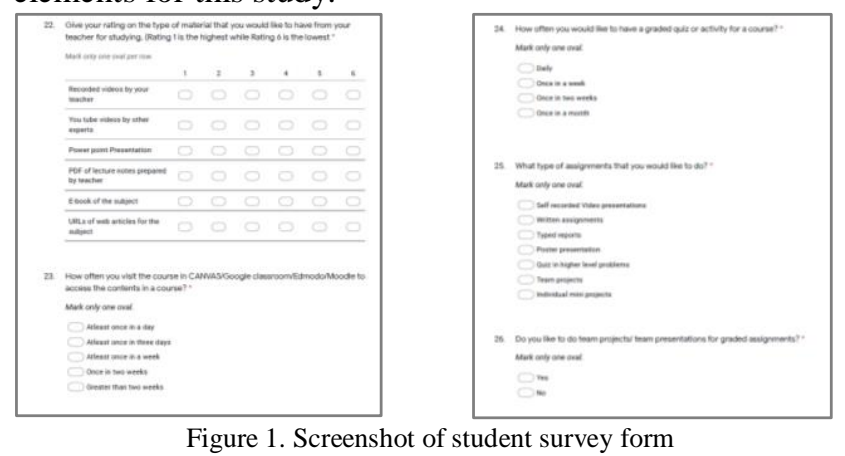

Table 3. Faculty survey parameters considered for this study

\begin{tabular}{|l|}
\hline \multicolumn{1}{|c|}{ Parameters } \\
\hline Total year of experience \\
\hline Online lecture per week \\
\hline Delivery mode (Live lecture/self -recorded/YouTube videos \\
\hline Online conferencing tool used \\
\hline Type of learning materials used (E-book, Specially designed \\
Notes, Pre-recorded lectures, YouTube videos, \\
\hline $\begin{array}{l}\text { Interactive tools used during synchronous sessions (Chat box, } \\
\text { Online interactive tool, Whatsapp, Open questions) }\end{array}$ \\
\hline $\begin{array}{l}\text { Types of assessment elements (Quizzes, Collaborative } \\
\text { assignments, Graded discussions, Homework, Open book test) }\end{array}$ \\
\hline
\end{tabular}


From the observed responses, research question 1 is addressed by the rank analysis from the responses given by the students. The responses from the students are listed and majority vote method is chosen to give the ranking for the elements. As the research study intends to find the influence of teaching experience in the transformation to online teaching, the responses from the teachers are analysed based on the ranks given to the elements by the students. As there are four different groups of teachers with different teaching experience and the data collected do not follow any specific distribution, one-way ANOVA on rank (Kruskal-Wallis) test is for checking the hypothesis. The study assumes a NULL hypothesis that there is NO significant difference in the practice of online elements among the different groups of teachers. If the NULL hypothesis got rejected, it is obvious that there exists significant difference in the practice and preference of online elements. If the NULL hypothesis is accepted for few elements, a Mann Whitney U test is used to find with the data of less experienced teachers (Group G1) and long-serving teachers (Group G4) to verify that there exists difference among these two groups of teachers.

\section{Results}

This section of the paper depicts the results in terms of students' preferences to different online elements and matching teachers' responses.

\subsection{Student preferences}

As there are 3 different components in online learning, the students' preferences on the online elements of these components are recorded as given in Table 2. Ranking of the preferences is made and the most preferred elements in the three components are visualized in Figures 2, 3,4 and 5.

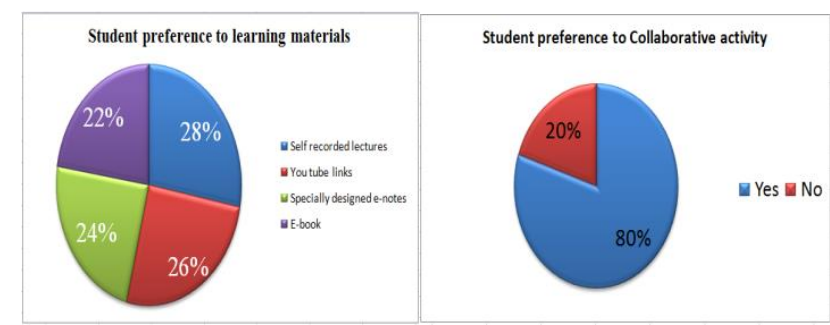

Figure 2. Learning material Figure 3: Preference to Collab. activities

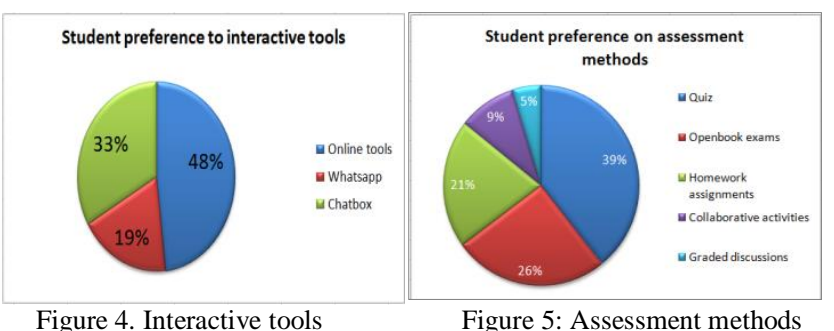

From the results obtained from the student inputs, the ranking of the different elements is depicted in Figure 6.

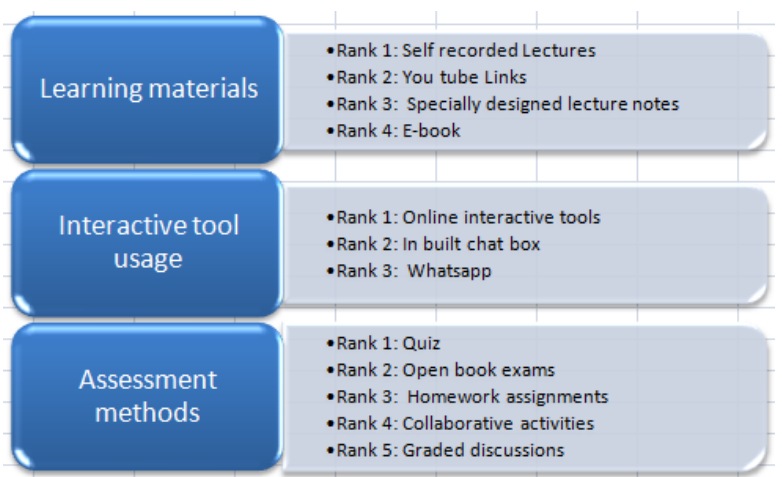

Figure 6. Ranking of student preferences

\subsection{Teachers' practices}

This section analyzes the responses to the survey questionnaire interms of different teacher groups as tabulated in Table 1. Figures 7 shows the different types of materials used by the teachers groupwise in the same order as expected by the student. For e.g. $40 \%$ of usage of self recorded lectures is by group G1 while it is less than $10 \%$ for group G4. While the usage of YouTube links by external experts are $35 \%$ by group $\mathrm{G} 1$, it gradually reduces to $20 \%$ in group G4. It shall be found from the figure that the more usage of any learning material is done by group G1 than any other groups. Figure 8 illustrates the number of different materials used by different teacher groups. It shall be found that G1 are the teachers which uses more than 1 type of material.

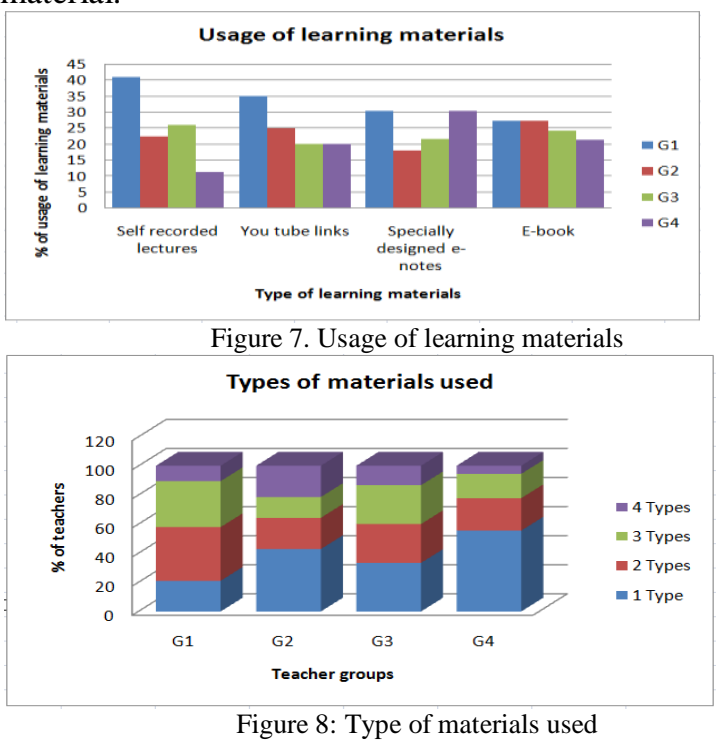

Regarding the content delivery component of online learning, Figures 9 and 10 shows its two elements: Usage of interactive tools and practice of collaborative activities. Figure 9 shows the usage of interactive tools in the order expected by the students. Group G1 has the maximum share of the usage of online tools while maximum teachers in Group G4 use chat box. Also, from Figure 10, it shall be understood that practice of collaborative activities is more in group G1 and gradually decreases to group G4. 


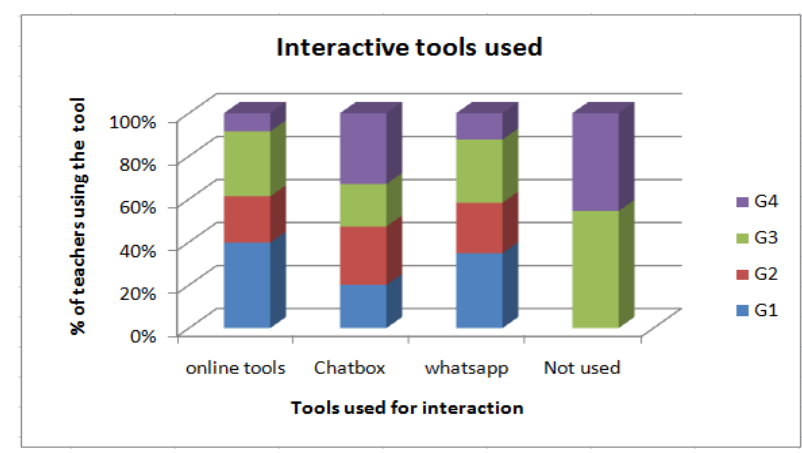

Figure 9. Usage of interactive tools

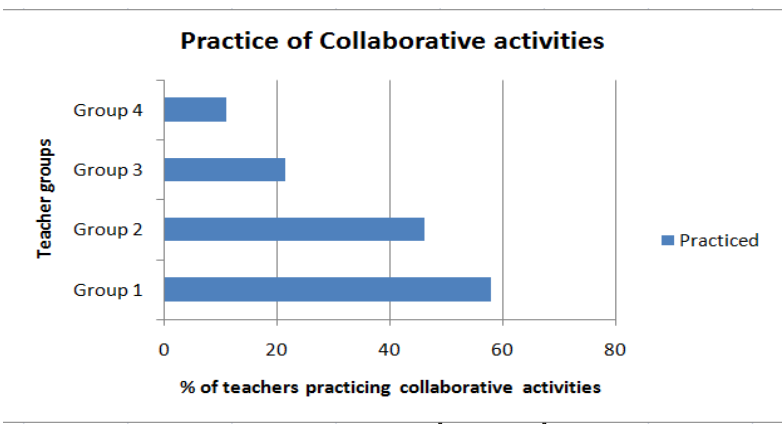

Figure 10: Practice of collaborative activities

Figures 11 and 12 show the usage of various assessment methods in the same order matching the students' ranking and number of different methods respectively. Here again, it shall be inferred that group G1 readily uses all the assessment methods more than the other groups. In many assessment methods, group G4 seems to be the group of lesser usage. The same shall be inferred from Figure 12.

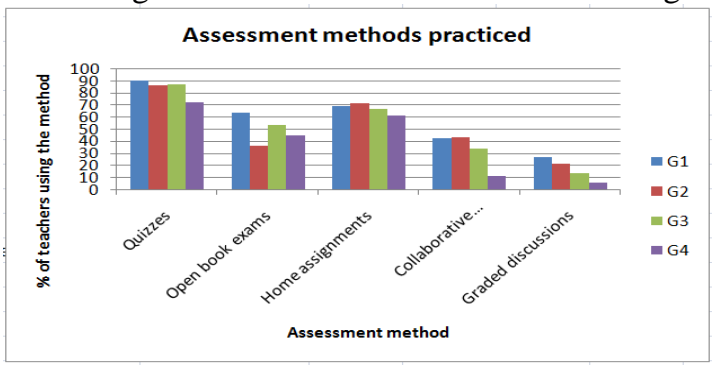

Figure 11. Usage of assessment methods

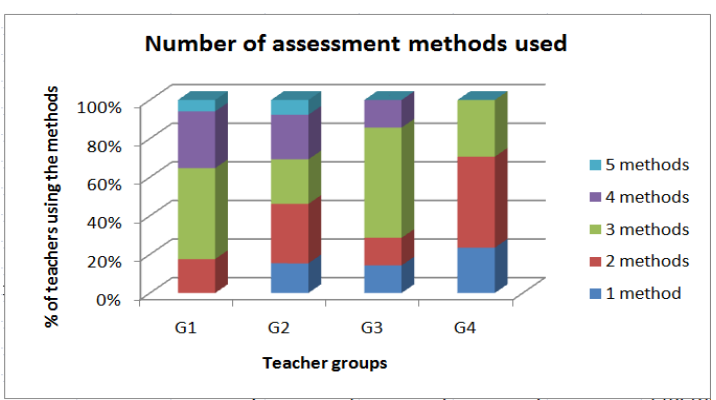

Figure 12: Type of assessment methods used

\section{Discussion on results}

This section of the paper discusses the results that are obtained from the responses. Considering the usage of learning materials, from figures 7 and 8 , it can be understood that teachers belong to group G1 has used a greater number of different tools and also according to the students' expectations than the other groups. From figures 9 and 10, it shall be understood that the practice of expected tools is better in group G1. There are teachers in group G3 and G4 who have not used any interactive tool. Also, the rate of collaborative activities decreases from G1 to G4. The figure 11 and 12 shows the decreasing slope in the usage of assessment methods and the number of different assessment methods used. For e.g., none of the teachers in group G1 uses a single method for assessment while there are teachers in group G3 and G4 who use only single method for assessment. Though the visualized data analysis may help to declare that increase in teaching experience is an influencing factor for rapid transformations in the perspective of online learning, there is essentially a need for statistical analysis. Hence, Kruskal-Wallis test is performed to find whether there exists significant difference between all the groups and MannWhitney $U$ test is performed to find whether there exists significant difference between individual groups as this research articles tries to explore the transformation in terms of teaching experience. Table 4 lists the different p-values obtained. The p-values that show significant differences are highlighted in the table.

Table 4. Statistical analysis of all online elements

\begin{tabular}{|c|c|c|c|c|c|}
\hline \multirow{3}{*}{$\begin{array}{c}\text { Online } \\
\text { element }\end{array}$} & & \multicolumn{4}{|c|}{ Individual groups (Mann-Whitney U Test) } \\
\hline & $\begin{array}{c}\text { All } \\
\text { groups }\end{array}$ & $\begin{array}{c}\text { G1 Vs } \\
\text { G2 }\end{array}$ & G1 V G3 & $\begin{array}{c}\text { G2 Vs } \\
\text { G4 }\end{array}$ & G1 Vs G4 \\
\hline & p-value & p-value & p-value & p-value & p-value \\
\hline \multicolumn{6}{|c|}{ Learning material } \\
\hline $\begin{array}{l}\text { No. of } \\
\text { learning } \\
\text { materials } \\
\text { used }\end{array}$ & .36079 & 28096 & $\begin{array}{c}0.3372 \\
4\end{array}$ & 0.142674 & 03288 \\
\hline $\begin{array}{l}\text { Learning } \\
\text { materials } \\
\text { according to } \\
\text { students' } \\
\text { expectations }\end{array}$ & 0.15619 & $\begin{array}{c}0.1586 \\
6\end{array}$ & $\begin{array}{c}0.3120 \\
7\end{array}$ & $\begin{array}{c}0.2236 \\
3\end{array}$ & .00657 \\
\hline \multicolumn{6}{|c|}{ Content Delivery: Active learning and Collaborative learning } \\
\hline $\begin{array}{l}\text { Online } \\
\text { interactive } \\
\text { tools }\end{array}$ & $\begin{array}{c}0.2564 \\
7\end{array}$ & 0.1335 & $\begin{array}{c}0.2388 \\
5\end{array}$ & 0.14 & .01044 \\
\hline $\begin{array}{l}\text { Collaborativ } \\
\text { e activities }\end{array}$ & 0.06555 & 0.2946 & 0.04006 & 0.05821 & 0.00776 \\
\hline \multicolumn{6}{|c|}{ Assessment methods } \\
\hline $\begin{array}{l}\text { No. of } \\
\text { methods } \\
\text { used }\end{array}$ & 0.02535 & $\begin{array}{c}0.1378 \\
6\end{array}$ & $\begin{array}{c}0.0985 \\
3\end{array}$ & $\begin{array}{c}.0427 \\
2\end{array}$ & .00025 \\
\hline $\begin{array}{l}\text { Assessment } \\
\text { according to } \\
\text { students' } \\
\text { expectations }\end{array}$ & 0.03326 & $\begin{array}{c}0.1131 \\
4\end{array}$ & $\begin{array}{c}0.1056 \\
5\end{array}$ & $\begin{array}{c}0.0901 \\
2\end{array}$ & $\begin{array}{c}0.0019 \\
3\end{array}$ \\
\hline
\end{tabular}

From Table 4, it shall be inferred that there is no significant difference in usage of learning materials, online interactive tools and collaborative learning activities among all the groups. Hence individual group analysis is made. From the individual analysis with Mann-Whitney $U$ test having pvalue $<0.05$ for rejecting NULL hypothesis, it is obvious that there exists significant difference among groups G1 \& G4 in all the online elements. It can also be inferred that there exists significant difference between G1 and G3 in usage of collaborative activities. Also, from the different assessment methods used, there exists significant difference among the 
groups and hence proving the same hypothesis that the teachers of group G1 reflect more the expectations of students in the perspective of online teaching elements than the long-serving teachers of group G4. From these inferences, it shall be declared that long-serving teaching experience has a greater impact on the new transformations in using technology. From these results, it shall be concluded that long-serving teaching experience may stand as barrier for rapid transformations to technology during online teaching. These findings have also opened avenues for increase in training programs in technology-based teaching and learning especially for long-serving teachers. Table 5 recommends different in-house training programs in different elements of online learning as per the results obtained. A similar study shall be performed in the institutions to identify the training needs.

Table 5. Recommendation of training programs

\begin{tabular}{|l|l|l|}
\hline Training parameter & Target groups & Helping group \\
\hline Self-recorded lectures & $\mathrm{G} 2, \mathrm{G} 3$ and G4 & $\mathrm{G} 1$ \\
\hline Specially designed e-notes & $\mathrm{G} 2$ \& G3 & $\mathrm{G} 1, \mathrm{G} 4$ \\
\hline $\begin{array}{l}\text { Identification of expert } \\
\text { lecture in You Tubes }\end{array}$ & $\mathrm{G} 2, \mathrm{G} 3$ \& G4 & $\mathrm{G} 1$ \\
\hline Online interactive tools of & $\mathrm{G} 2, \mathrm{G} 3$ \& G4 & $\mathrm{G} 1$ \\
\hline $\begin{array}{l}\text { Implementation } \\
\text { collaborative activities in } \\
\text { class } \\
\text { and in assessment }\end{array}$ & $\mathrm{G} 1$ \\
\hline $\begin{array}{l}\text { Usage of online tools in } \\
\text { assessment }\end{array}$ & $\mathrm{G} 2, \mathrm{G} 3$ \& G4 & $\mathrm{G} 1$ \\
\hline $\begin{array}{l}\text { Usage of open book exams } \\
\text { can be given to all as the effectiveness } \\
\text { of the conducted open book } \\
\text { exams have to be analysed (not under } \\
\text { the scope of this research study) }\end{array}$ \\
\hline
\end{tabular}

\section{Conclusion}

This study is made with the faculty and student team of an institution. The study helps to understand the influence of teaching experience in rapid transformation to online teaching. The research analysis revealed the expectations of the students in an online environment and finds whether the different teacher groups are using appropriate tools as expected by the students. The results obtained have enabled us to conclude that long-serving teaching experience shall be a difficulty factor that may inhibit the sudden transformations to technology teaching. The study has showed the need of conducting focused training programs in terms of teaching experience. This study shall be extended to find the impact analysis of organizing such training programs in near future. In this research work, few results of hypothesis testing had higher p-values indicating that the data is not sufficient to come to any fixed conclusion. Hence, such type of surveys and interviews shall be performed with increased number of teachers and students to arrive at a concrete conclusion. If the numbers are scaled higher, it may definitely lead to more insights on the group of teachers and effective decisions on "Which group of teachers needs specific training programs?"

\section{Acknowledgement}

We thank all of our teachers and students who participated in this survey.

\section{References}

[1] Batane, T., \& Ngwako, A. (2017). Technology use by pre-service teachers during teaching practice: Are new teachers embracing technology right away in their first teaching experience? Australasian Journal of Educational Technology, 33(1).

[2] Bingimlas, K. A. (2009). Barriers to the successful integration of ICT in teaching and learning environments: A review of the literature. Eurasia Journal of Mathematics, science and technology education, 5(3), 235-245.

[3] Conrad, D. (2004). University instructors' reflections on their first online teaching experiences. Journal of Asynchronous Learning Networks, 8(2), 31-44.

[4] Hall, B. C. (2008). Investigating the relationships among computer self-efficacy, professional development, teaching experience, and technology integration of teachers (Doctoral dissertation, University of Cincinnati).

[5] Han, I., Shin, W. S., \& Ko, Y. (2017). The effect of student teaching experience and teacher beliefs on preservice teachers' self-efficacy and intention to use technology in teaching. Teachers and Teaching, 23(7), 829-842.

[6] Inan, F. A., \& Lowther, D. L. (2010). Factors affecting technology integration in K-12 classrooms: A path model. Educational technology research and development, 58(2), 137-154.

[7] Kim, K. J., \& Bonk, C. J. (2006). The future of online teaching and learning in higher education. Educause quarterly, 29(4), 22-30.

[8] Mahdi, H. S., \& Al-Dera, A. S. A. (2013). The Impact of Teachers' Age, Gender and Experience on the Use of Information and Communication Technology in EFL Teaching. English Language Teaching, 6(6), 57-67.

[9] Sun, Y., Strobel, J., \& Newby, T. J. (2017). The impact of student teaching experience on pre-service teachers' readiness for technology integration: A mixed methods study with growth curve modeling. Educational Technology Research and Development, 65(3), 597629.

[10] Teo, T., \& Zhou, M. (2017). The influence of teachers' conceptions of teaching and learning on their technology acceptance. Interactive Learning Environments, 25(4), 513-527.

[11] Wilson, G., \& Stacey, E. (2004). Online interaction impacts on learning: Teaching the teachers to teach online. Australasian journal of educational technology, 20(1).

[12] Windes, D. L., \& Lesht, F. L. (2014). The effects of online teaching experience and institution type on faculty perceptions of teaching online. Online Journal of Distance Learning Administration, 17(1). 